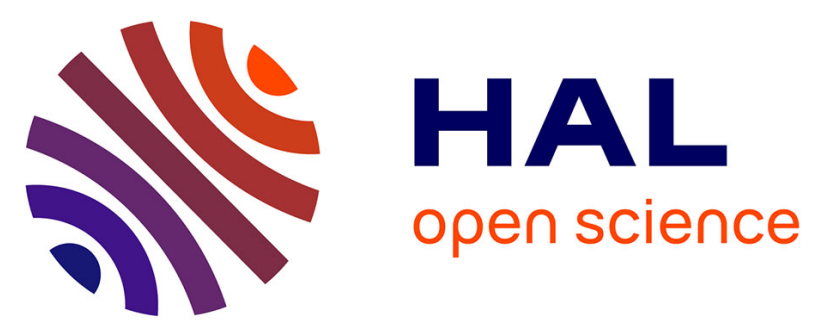

\title{
Bipolar Conduction Impact on Electrical Characteristics and Reliability of 1.2- and 3.5-kV 4H-SiC JBS Diodes
}

Pierre Brosselard, Nicolas Camara, Viorel Banu, Xavier Jordà, Miquel Vellvehi, Philippe Godignon, José del R. Millán

\section{- To cite this version:}

Pierre Brosselard, Nicolas Camara, Viorel Banu, Xavier Jordà, Miquel Vellvehi, et al.. Bipolar Conduction Impact on Electrical Characteristics and Reliability of 1.2- and 3.5-kV 4H-SiC JBS Diodes. IEEE Transactions on Electron Devices, 2008, 55 (8), pp.1847 - 1856. 10.1109/TED.2008.926636 . hal-00369497

\section{HAL Id: hal-00369497 \\ https://hal.science/hal-00369497}

Submitted on 3 Jun 2009

HAL is a multi-disciplinary open access archive for the deposit and dissemination of scientific research documents, whether they are published or not. The documents may come from teaching and research institutions in France or abroad, or from public or private research centers.
L'archive ouverte pluridisciplinaire HAL, est destinée au dépôt et à la diffusion de documents scientifiques de niveau recherche, publiés ou non, émanant des établissements d'enseignement et de recherche français ou étrangers, des laboratoires publics ou privés. 


\title{
Bipolar Conduction Impact on Electrical Characteristics and Reliability of 1.2- and 3.5-kV 4H-SiC JBS Diodes
}

\author{
Pierre Brosselard, Nicolas Camara, Viorel Banu, Xavier Jordà, Miquel Vellvehi, \\ Philippe Godignon, and José Millán, Member, IEEE
}

\begin{abstract}
H-SiC Junction Barrier Schottky (JBS) diodes (1.2 and $3.5 \mathrm{kV}$ ) have been processed using the same technology with two different layouts. From $4 \mathrm{~A}$ and for the whole temperature range, the 3.5-kV diodes exhibit a bipolar conduction independent of the layout. However, the behavior of the 1.2-kV diodes depends on the design. At $500 \mathrm{~V}-300{ }^{\circ} \mathrm{C}$, the leakage current is only $100 \mathrm{nA}$ and $10 \mu \mathrm{A}$ for the 3.5- and 1.2-kV diodes, respectively. The switch-off performances show a reverse peak current of only $50 \%$ of the nominal current at $300{ }^{\circ} \mathrm{C}$ for all JBS diodes. The JBS diodes have a surge current capability of around $80 \mathrm{~A}$, two times higher than the Schottky diodes. DC electrical stresses are performed during $50 \mathrm{~h}$, and all the 1.2-kV diodes exhibit no bipolar degradation. Nevertheless, some slight bipolar degradation is observed in 3.5-kV JBS diodes. Electroluminescence measurements exhibit the expansion of stacking faults in $3.5-\mathrm{kV}$ diodes unlike in $1.2-\mathrm{kV}$ diodes.
\end{abstract}

Index Terms-Junction Barrier Schottky (JBS), merged p-i-n Schottky, rectifier, reverse recovery, Schottky, silicon carbide (SiC), surge current, ultrafast diodes.

\section{INTRODUCTION}

D IAMOND, gallium nitride $(\mathrm{GaN})$, and silicon carbide (SiC) are wide-bandgap (WBG) semiconductors theoretically having the best properties (critical electric field, mobility and intrinsic concentration) for power electronics applications. Up to date, it is still difficult to find high-quality diamond material, and its process technology is rather hard. GaN devices, mainly epitaxial $\mathrm{GaN}$ layers on $\mathrm{SiC}, \mathrm{Si}$, or sapphire substrates, are mainly suitable for RF applications (commercial devices are available from OKI, Nitronex, RFMD, etc.), and lateral power devices up to $600 \mathrm{~V}$ (Velox Semiconductor) are also available. Because of the tradeoff between the on-resistance and the breakdown voltage, $\mathrm{GaN}$ and $\mathrm{SiC}$ lateral devices are limited to about $1 \mathrm{kV}$. Therefore, the best option to reach high-voltage level is the vertical device architecture using a low defective

Manuscript received November 29, 2007; revised March 26, 2008. This work was supported in part by the European Commission under the ESCAPEE Project GRD1-2000-25337, by the European Space Agency under the CHPCA project, and by the "Spanish Science and Education Ministry" under the SpaceSiC Project TEC2005-07937-C02. The review of this paper was arranged by Editor T. Kimoto.

The authors are with the Centro Nacional de Microelectrónica-Instituto de Microelectrónica de Barcelona-Consejo Superior de Investigaciones Científicas, National Center of Microelectronics, 08193 Barcelona, Spain (e-mail: Pierre.brosselard@cnm.es).

Color versions of one or more of the figures in this paper are available online at http://ieeexplore.ieee.org.

Digital Object Identifier 10.1109/TED.2008.926636 starting substrate on which a homoepitaxy is feasible, which is the case only for $\mathrm{SiC}$ up to now. For $\mathrm{SiC}$, the modified Lely method [1] is successfully used by manufacturers (such as CREE) to produce $\mathrm{SiC}$ substrates with a micropipe density low enough for manufacturing large-area power devices. Then, the chemical vapor deposition (CVD) technique is employed to grow high-quality $\mathrm{SiC}$ epitaxial layers [2]. Due to that, the most mature WBG semiconductor for developing 600-V and higher breakdown voltage devices is currently $\mathrm{SiC}$.

Since 2001, Infineon has been commercializing 600- and 1200-V Schottky barrier diodes (SBDs). Other companies like CREE, APT, Semelab, etc., sell SiC SBDs in the 300- to $1200-\mathrm{V}$ range with nominal currents from 6 to $20 \mathrm{~A}$. In some power electronic systems like power factor correction, a $40 \%$ decrease on the losses, a reduction of the system size, and a decrease of the cooling system [3] are feasible just replacing the Si bipolar diode by a SiC SBD. Nevertheless, this replacement may impact on the surge current capability [4] and the leakage current level. Thus, since 2006, Infineon has been commercializing a second generation of 600-V SBD based on the Junction Barrier Schottky (JBS) diode [4]. This device mixes Schottky contact regions on $\mathrm{N}$ with $\mathrm{P}^{+}$stripes or dots regions, locally forming $\mathrm{p}-\mathrm{n}$ junctions. This way, the metallic anode contact must be Schottky on the N-region and ohmic on the $\mathrm{P}^{+}$region. The advantages of the JBS diode in comparison with the SBD lie on the increase of the surge current capability in the forward mode and the decrease of the leakage current in the reverse mode [5], [6]. In the forward mode, the JBS diodes could show similar electrical characteristics than the SBDs, depending on the $\mathrm{P}^{+} / \mathrm{N}$ area ratio. When compared with the bipolar (p-i-n) diode, the JBS diode presents a higher differential on-resistance, even when working in the bipolar mode, due to the lower effective area of the $p-n$ junction. However, because of bipolar degradations [7], lack of current limitation with temperature, and high turn-off losses, p-i-n diodes are limited in terms of reliability, paralleling, and power losses. On the other hand, SiC JBS diodes seem to show much lower bipolar degradations, current limitation with temperature, and very low turn-off losses. Therefore, SiC JBS diodes are a promising alternative for high-voltage diodes using either largearea devices or paralleling several dice in order to increase the current level of such modules.

To summarize, SiC JBS diodes show lower leakage current and higher surge current capabilities than SiC Schottky diodes 


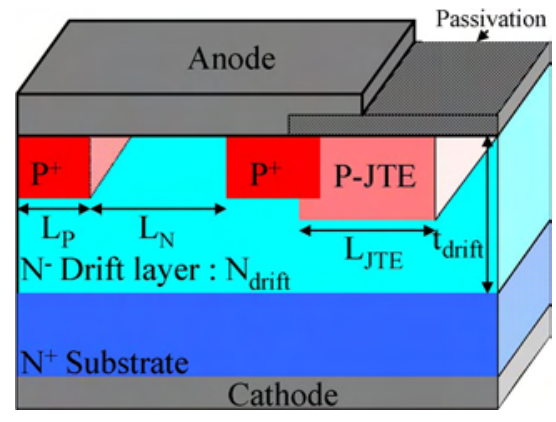

Fig. 1. Schematic cross section of a 4H-SiC JBS diode.

and seem to be more suitable than $\mathrm{SiC}$ p-i-n diodes in terms of reliability, paralleling, and low turn-off losses for high-voltage applications.

This paper analyzes the performances of 1.2- and 3.5-kV JBS diodes with the same layout and the same process technology. After presenting the cross section of the JBS diodes and its process technology, the activation of the bipolar conduction on the 1.2- and 3.5-kV diodes, the reverse electrical characteristics, and the turn-off current waveforms will be analyzed for different layouts. Concerning reliability aspects, the surge current capability and electrical stress will also be discussed. Finally, the electroluminescence characterizations will be detailed in order to show the activation or not of stacking faults (SFs).

\section{4H-SiC JBS DIODES}

\section{A. Device Concept}

Fig. 1 shows a schematic cross section of a JBS diode, where we can infer the merging between SBD and p-i-n areas. In forward mode, at $V_{\mathrm{AK}}>1 \mathrm{~V}$ and depending on the anode metal barrier, the diode enters the unipolar conduction due to the Schottky component. At higher voltage drops, the bipolar conduction mode gets activated. The bipolar activation voltage depends on numerous parameters, such as the $\mathrm{P}^{+}$doping profile, the $\mathrm{P}^{+}$ohmic contact resistance, the stripes or spots dimensions, etc. In reverse mode, the JBS diode shows a leakage current lower than the SBDs due to the presence of the space charge region generated by the $\mathrm{p}-\mathrm{n}$ junction regions in order to limit the electric field at the semiconductor surface. In switching mode, JBS diodes exhibit or not space recovery charges depending on the activation of the bipolar conduction mode.

The two main geometrical parameters of the JBS diodes are the $\mathrm{P}^{+}$ring length $\left(L_{P}\right)$ and the spacing between two $\mathrm{P}^{+}$ rings $\left(L_{N}\right)$ [Fig. 1(a)]. These parameters will determine the tradeoff between forward conduction, surge current capability, reverse current leakages, and switching times, as shown in the following sections.

\section{B. Design and Process Technology}

Different diode layouts and areas have been designed and included in our mask set. Parallel stripes design is used to implement the $\mathrm{P}^{+}$junctions. For high-voltage periphery protection, we have chosen a single-zone $120-\mu \mathrm{m}$ junction termination
TABLE I

SUMMARY OF THE DIFFERENT GEOMETRICAL CHARACTERISTICS FOR EACH JBS DIODE

\begin{tabular}{cccc}
\hline \hline Diode name & $\mathrm{L}_{\mathrm{P}}(\mu \mathrm{m})$ & $\mathrm{L}_{\mathrm{N}}(\mu \mathrm{m})$ & Diode area $\left(\mathrm{mm}^{2}\right)$ \\
\hline D2 & 2 & 3 & 0.16 \\
D5 & 2 & 3 & 2.56 \\
D6 & 3 & 4 & 2.56 \\
\hline \hline
\end{tabular}

extension (JTE). Table I shows the different parameters of the fabricated diodes.

$4 \mathrm{H}-\mathrm{SiC}$ JBS diodes $(1.2 \mathrm{kV})$ have been manufactured on a $7 \mu \mathrm{m}\left(t_{\text {drift }}\right) 8 \times 10^{15} \mathrm{~cm}^{-3}\left(N_{\text {drift }}\right)$ N-type epilayer-selected micropipe density, whereas the $3.5-\mathrm{kV}$ epilayer properties are $30 \mu \mathrm{m}\left(t_{\text {drift }}\right)$ and $1.5 \times 10^{15} \mathrm{~cm}^{-3}\left(N_{\text {drift }}\right)$ ultralow micropipe density. The same process technology with the same set of masks has been employed for both $1.2-$ and $3.5-\mathrm{kV}$ diodes. The $\mathrm{P}^{+}$region is performed by multiple $\mathrm{Al}$ implantation at $400{ }^{\circ} \mathrm{C}$. Energies ranged from 20 to $160 \mathrm{keV}$ to get a $0.25-\mu$ m-deep square profile. Then, the JTE is formed by another multiple Al implantation performed at $300{ }^{\circ} \mathrm{C}$. The maximum implantation energy is around $360 \mathrm{keV}$ (double charge) to get a $0.45-\mu \mathrm{m}$ junction depth. Samples are annealed at $1650^{\circ} \mathrm{C}$ during $30 \mathrm{~min}$ in an $\mathrm{Ar}$ ambient. Then, a CVD $0.5 \mu \mathrm{m}-\mathrm{SiO}_{2} / 1 \mu \mathrm{m}-\mathrm{Si}_{3} \mathrm{~N}_{4}$ bilayer is deposited as a first passivation layer. The cathode back side metallization consists of a $\mathrm{Ni}$ layer annealed at $950{ }^{\circ} \mathrm{C}$ during 2 min, whereas the anode metallization is Ti/Ni.

\section{Metallization and Thermal Annealing}

The main challenge concerning the SiC JBS diode process technology is to perform, with the same metallization and postannealing, an ohmic contact on the $\mathrm{P}^{+}$region and a Schottky contact on the $\mathrm{N}$ region. In one of our previous works, a Ti/Ni bilayer and a Ni layer have been used as anode contact on SBDs [8], [9]. In forward mode, the Ti/Ni contact is preferable due to a lower threshold voltage in comparison with Ni. Nevertheless, in reverse mode, the Ni contact shows lower leakage currents than the Ti/Ni contact. Moreover, a performant ohmic contact can be obtained with $\mathrm{Ni}$ and $\mathrm{Ti} / \mathrm{Ni}$ on $\mathrm{P}^{+}$regions with an adequate thermal treatment. Therefore, these two different metallizations seem suitable for JBS diodes, and they are used in order to compare them. D2 JBS diodes (Table I) are characterized with probes up to $100 \mathrm{~mA}$ in forward conduction. At this forward current level, the bipolar conduction is not yet activated. Table II summarizes the main electrical properties in forward mode for three different metallization-annealing (in $\mathrm{N}_{2}$ ambient during $2 \mathrm{~min}$ ) schemes. In reverse mode, at $100 \mathrm{~V}$, the leakage current is lower for the $\mathrm{Ni}-700{ }^{\circ} \mathrm{C}$ metallization than the other schemes. Moreover, $81 \%$ of the diodes with $\mathrm{Ni}-700{ }^{\circ} \mathrm{C}$ metallization shows $V_{\mathrm{br}}$ higher than $500 \mathrm{~V}$, and less than $60 \%$ of the diodes with other metallization schemes shows this high-voltage capability. This is the reason why the $\mathrm{Ni}-700{ }^{\circ} \mathrm{C}$ metallization is finally chosen to develop the JBS devices. One can notice that for this metallization, the differential resistance $\left(R_{\text {on }}\right)$ is the lowest one, which is another advantage of this metallization. In addition, similar results obtained on 
TABLE II

Average Values of the Main Electrical Characteristics on D2 Diodes for the Three DifFERENT MetalliZATIONANNEALING APPROACHES

\begin{tabular}{lcccc}
\hline \hline & $\begin{array}{c}\mathrm{V}_{\mathrm{F}}(\mathrm{V}) \\
\text { @ } 100 \mathrm{~A} \cdot \mathrm{cm}^{-2}\end{array}$ & $\begin{array}{c}\mathrm{R}_{\text {on }}\left(\mathrm{m} \Omega \cdot \mathrm{cm}^{2}\right) \\
@ 30 \mathrm{~A} \cdot \mathrm{cm}^{-2}\end{array}$ & $\begin{array}{c}\mathrm{I}_{\mathrm{r}}(\mathrm{nA}) \\
\text { @ } 100 \mathrm{~V}\end{array}$ & $\begin{array}{c}\text { Yield (\%) } \\
\text { @ 500V }\end{array}$ \\
\hline Ti/Ni $700^{\circ} \mathrm{C}$ & 1.9 & 3.65 & 80 & 60 \\
$\mathrm{Ni} 700^{\circ} \mathrm{C}$ & 2.2 & 3.05 & 20 & 81 \\
$\mathrm{Ni} 500^{\circ} \mathrm{C}$ & 1.6 & 4.35 & 40 & 59 \\
\hline \hline
\end{tabular}

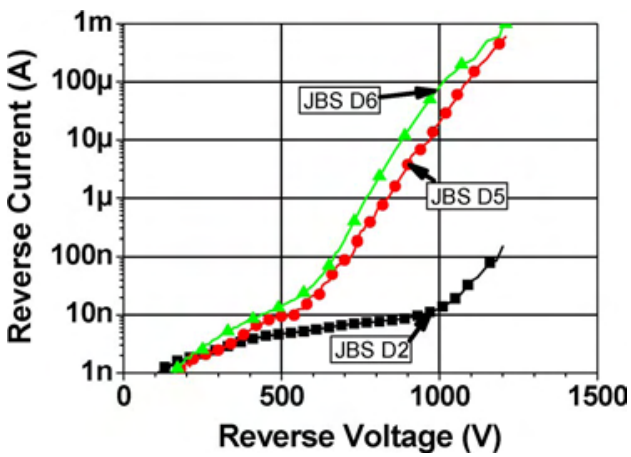

Fig. 2. Reverse electrical characteristics of $1.2-\mathrm{kV}$ fabricated diodes for various design and active areas.

3.5-kV diodes confirm that the best anode metallization for JBS diodes is nickel annealed at $700{ }^{\circ} \mathrm{C}$ during $2 \mathrm{~min}$.

\section{Packaging}

A second metallization consisting of a 3- $\mu \mathrm{m} \mathrm{Al} \mathrm{layer} \mathrm{for} \mathrm{the}$ anode and a Ni/Au bilayer for the cathode is also deposited. The process ends up with a final polyimide passivation for highvoltage capability. The diodes have been packaged on a direct copper-bonded ceramic test package with similar dimensions than a standard TO-247 package using a high-temperature $\mathrm{Au} / \mathrm{Ge}$ alloy as die attach to characterize them between $25{ }^{\circ} \mathrm{C}$ and $300{ }^{\circ} \mathrm{C}$ (case temperature).

\section{Static Electrical Characterizations}

\section{A. Reverse Mode}

The on-wafer reverse characterization of the diodes was done at room temperature in a Galden bath to avoid arcing destruction. Figs. 2 and 3 report on the typical reverse characteristics obtained from the measurement of several diodes measured on different areas of the sample. The $1.2-\mathrm{kV}$ diodes are characterized using a $370 \mathrm{~A}$ Tektronix curve tracer, whereas a $10-\mathrm{kV}$ voltage source coupled with a pico-ampermeter to measure the current is used for the $3.5-\mathrm{kV}$ devices. Let us mention that leakage currents lower than $1 \mathrm{nA}$ cannot be measured with the curve tracer. D6-type (see Table I) diodes show a leakage current higher than D5 over the whole sample area independent of the epilayer thickness and doping level. This is due to the higher Schottky component in D6 than in D5 due to the larger $L_{N}$. It results in a higher electric field at the interface for a given reverse voltage bias. The small-area diode D2 shows a much lower leakage current than the large-area diodes, in the range of 1000 times lower at $1000 \mathrm{~V}$. It does not reflect the area

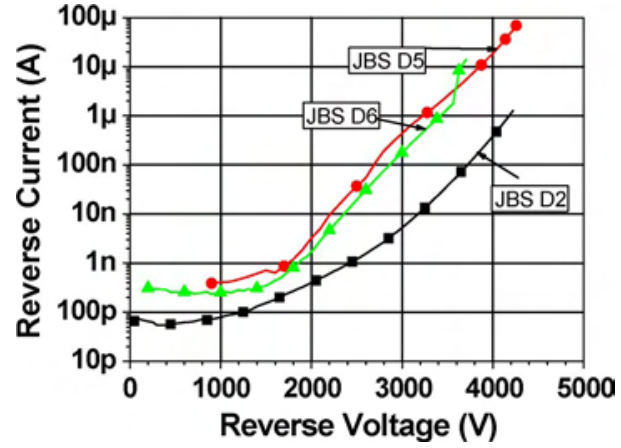

Fig. 3. Reverse electrical characteristics of $3.5-\mathrm{kV}$ fabricated diodes for various design and active areas.

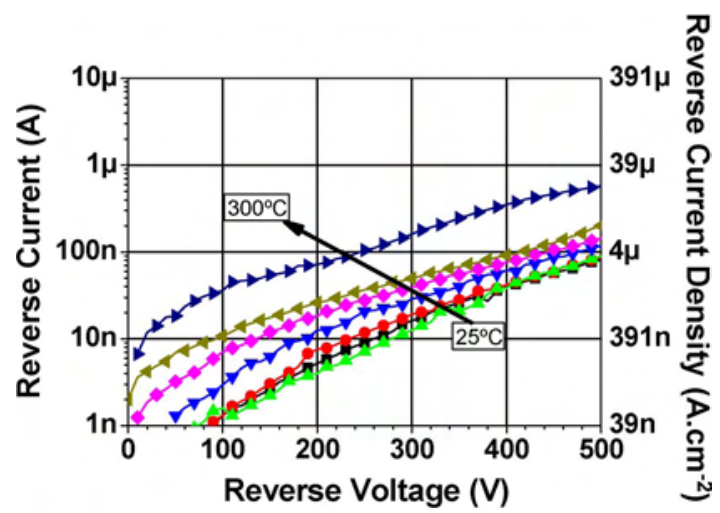

Fig. 4. Reverse electrical characteristics of $1.2-\mathrm{kV}$ D5 diode from $25^{\circ} \mathrm{C}$ to $300{ }^{\circ} \mathrm{C}$.

ratio (16 times) between the diodes, so it can be also attributed to the starting material quality.

On the contrary, for $3.5-\mathrm{kV}$ diodes (Fig. 3), the leakage current of D5 and D6 at $3500 \mathrm{~V}$ is only 20 times higher than that of D2, according to the ratio of their respective areas. This result evidences the impact of the quality of the starting material $(1.2 \mathrm{kV}$ on selected micropipes density and $3.5 \mathrm{kV}$ on ultralow micropipes density). Both large and small diodes show a breakdown voltage superior to $3.5 \mathrm{kV}$ depending on the breakdown criterion. In fact, one can distinguish various regions in the JBS reverse $I(V)$ characteristic; initially, at low reverse voltages (up to $1.8 \mathrm{kV}$ ), it exhibits a bipolar like reverse $I(V)$ curve, and then there is an increment of the $I(V)$ slope (like in a SBD). Therefore, our breakdown criterion for JBS is based on the reverse current density level $\left(40 \mu \mathrm{A} \cdot \mathrm{cm}^{-2}\right)$ corresponding to $1 \mu \mathrm{A}$ for the $2.56-\mathrm{mm}^{2}$ diodes.

The packaged diodes have been characterized in reverse mode up to $500 \mathrm{~V}$ by a Keithley K237 SMU in the $25{ }^{\circ} \mathrm{C}$ to $300{ }^{\circ} \mathrm{C}$ temperature range. Figs. 4 and 5 show the leakage current behavior up to $500 \mathrm{~V}$ ( $42 \%$ of the $V_{\mathrm{br}}$ ) of $1.2-\mathrm{kV}$ D5 and D6 diodes. This current is between $100 \mathrm{nA}$ and $1 \mu \mathrm{A}$ for D5, and between $1 \mu \mathrm{A}$ and $10 \mu \mathrm{A}$ for D6. As already seen in the $1.2-\mathrm{kV}$ diodes, this shift of the leakage current is due to the larger Schottky component of D6. Independent of the temperature, the $\mathrm{SiC}$ JBS diodes exhibit a lower leakage current than the 1.2-kV Si p-i-n diodes $\left(3 \mu \mathrm{A}-25^{\circ} \mathrm{C}, 10 \mathrm{~mA}-175{ }^{\circ} \mathrm{C}\right.$ at $\left.500 \mathrm{~V}\right)$ [10]. Whatever the layout, the $1.2-\mathrm{kV}$ JBS diodes are more suitable for power applications than the 1.2-kV Si p-i-n diodes. 


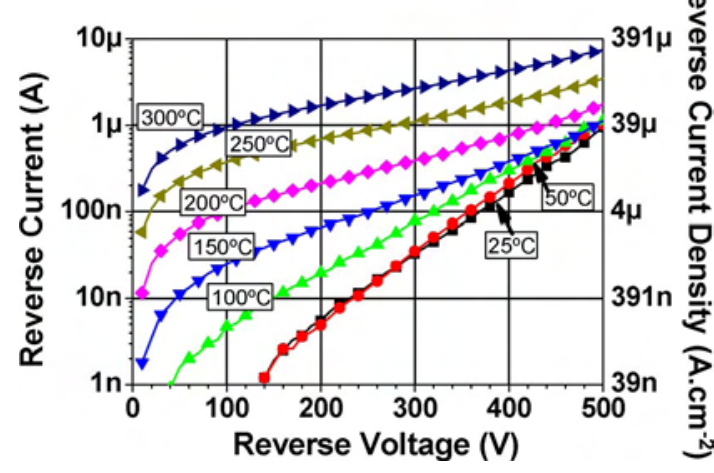

Fig. 5. Reverse electrical characteristics of $1.2-\mathrm{kV}$ D6 diode from $25^{\circ} \mathrm{C}$ to $300^{\circ} \mathrm{C}$.

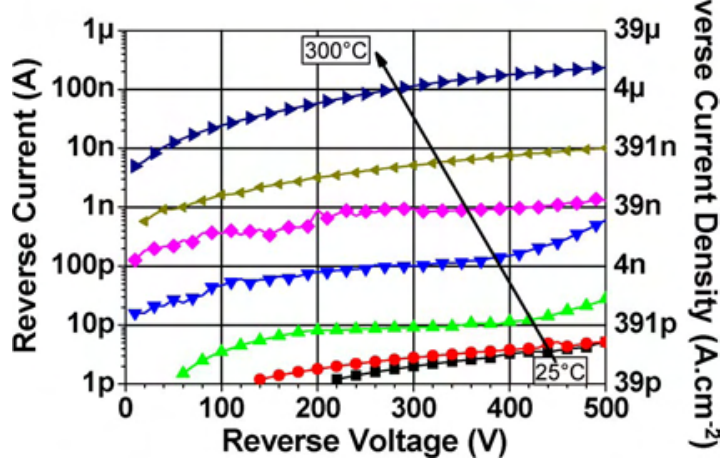

Fig. 6. Reverse electrical characteristics of $3.5-\mathrm{kV}$ D5 diode from $25{ }^{\circ} \mathrm{C}$ to $300{ }^{\circ} \mathrm{C}$

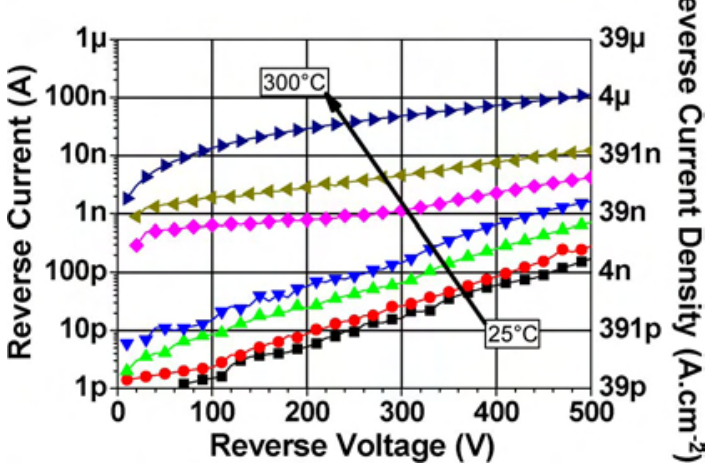

Fig. 7. Reverse electrical characteristics of $3.5-\mathrm{kV}$ D6 diode from $25{ }^{\circ} \mathrm{C}$ to $300{ }^{\circ} \mathrm{C}$.

Figs. 6 and 7 present the reverse leakage current of $3.5-\mathrm{kV}$ JBS up to $500 \mathrm{~V}\left(14 \%\right.$ of the $\left.V_{\mathrm{br}}\right)$. Below $100{ }^{\circ} \mathrm{C}$, the leakage current is lower than $1 \mathrm{nA}$, and at this current level, the measurements are not fully reliable due to our measurement setup limitations. At higher temperatures, the D5 and D6 leakage currents are almost equal. Indeed, the $3.5-\mathrm{kV}$ diodes are developed on a drift region having a lower doping level than the $1.2-\mathrm{kV}$ diodes. For this lower doping, the two designs we selected do not clearly impact the leakage current, maintaining a low electric field at the Schottky interface. For these $3.5-\mathrm{kV}$ diodes, leakage current differences could be seen with larger $L_{N}$ values.

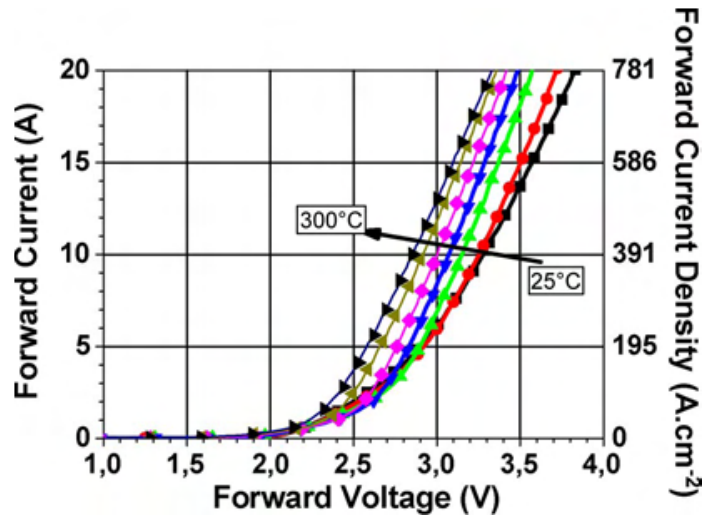

Fig. 8. Forward electrical characteristics of $1.2-\mathrm{kV}$ D5 diode from $25{ }^{\circ} \mathrm{C}$ to $300{ }^{\circ} \mathrm{C}$.

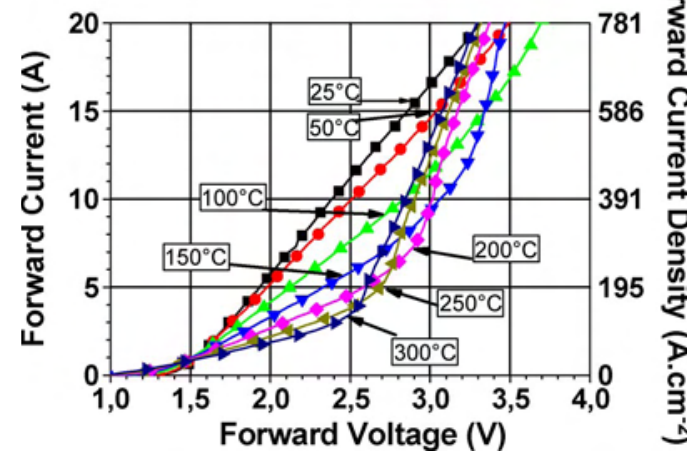

Fig. 9. Forward electrical characteristics of $1.2-\mathrm{kV}$ D6 diode from $25^{\circ} \mathrm{C}$ to $300{ }^{\circ} \mathrm{C}$.

\section{B. Forward Mode}

The 1.2-kV packaged diodes have been characterized in forward mode from $25^{\circ} \mathrm{C}$ to $300{ }^{\circ} \mathrm{C}$. As we can see, the forward characteristics strongly depend on the diode design (Figs. 8 and 9). The D5 design exhibits a negative thermal coefficient, i.e., the forward voltage drop decreases with temperature at a current level higher than $5 \mathrm{~A}$ in the whole temperature range. This diode has the larger bipolar component, and its behavior is typically bipolar [11]. At $25^{\circ} \mathrm{C}$ and $15 \mathrm{~A}$, the differential D5 diode resistance is $1.4 \mathrm{~m} \Omega \cdot \mathrm{cm}^{2}$, whereas the estimated value associated to the drift, substrate, and contact resistivities is $1.8 \mathrm{~m} \Omega \cdot \mathrm{cm}^{2}$. Under these conditions, the diode is in bipolar conduction with a low conductivity modulation. At $300{ }^{\circ} \mathrm{C}-$ $15 \mathrm{~A}$, the differential resistance is $1.1 \mathrm{~m} \Omega \cdot \mathrm{cm}^{2}$, whereas the estimated value associated to the drift, substrate, and contact resistivities is $3.9 \mathrm{~m} \Omega \cdot \mathrm{cm}^{2}$. At high temperature, the D5 diode is in pure bipolar mode.

The thermal behavior of the D6 is different. At low temperature $\left(25{ }^{\circ} \mathrm{C}\right.$ to $\left.50{ }^{\circ} \mathrm{C}\right)$, the conduction is purely unipolar up to $20 \mathrm{~A}$ due to a positive temperature coefficient and a lack of conductivity modulation in the drift region. Indeed, at $25{ }^{\circ} \mathrm{C}$ and $15 \mathrm{~A}$, the differential resistance is $2.4 \mathrm{~m} \Omega \cdot \mathrm{cm}^{2}$ compared to the estimated epilayer, substrate, and contact resistivities of $1.8 \mathrm{~m} \Omega \cdot \mathrm{cm}^{2}$. Let us note that the Schottky area of this diode represents $50 \%$ of the total areas, which explains this high differential resistance. At $300{ }^{\circ} \mathrm{C}$, a slope shift observed at 


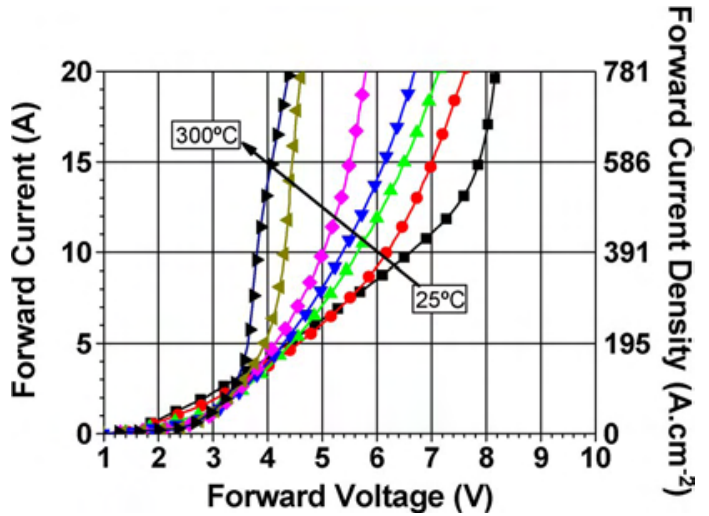

Fig. 10. Forward electrical characteristics of $3.5-k V$ D5 diode between $25{ }^{\circ} \mathrm{C}$ and $300{ }^{\circ} \mathrm{C}$

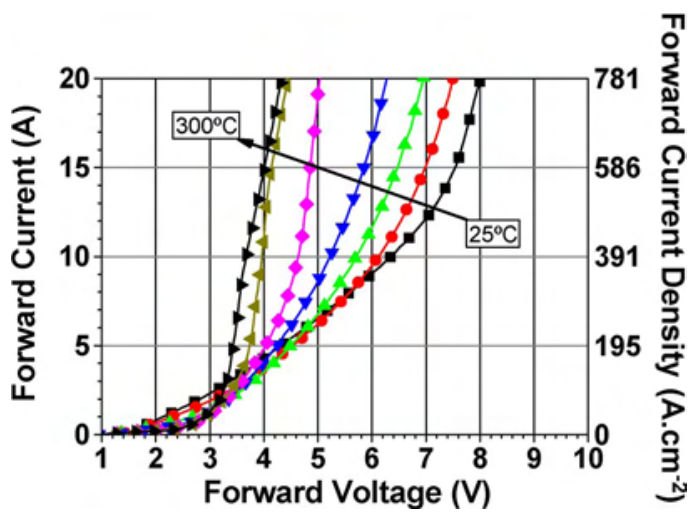

Fig. 11. Forward electrical characteristics of 3.5-kV D6 diode between $25^{\circ} \mathrm{C}$ and $300{ }^{\circ} \mathrm{C}$

4 A clearly proves the activation of the bipolar mode. Let us note that at $300{ }^{\circ} \mathrm{C}-15 \mathrm{~A}$, the differential resistivity of D6 is also $1.1 \mathrm{~m} \Omega \cdot \mathrm{cm}^{2}$. For all layouts under these conditions, a high conductivity modulation is always reached.

The $3.5-\mathrm{kV}$ packaged diodes have also been characterized in forward mode from $25{ }^{\circ} \mathrm{C}$ to $300{ }^{\circ} \mathrm{C}$ (Figs. 10 and 11). A similar behavior is observed on the two designs (D5 and D6). At $12 \mathrm{~A}-25^{\circ} \mathrm{C}$, a slope shift is observed, proving the activation of the bipolar mode. When the temperature increases, the slope shift is observed at a lower current level $\left(2 \mathrm{~A}\right.$ at $\left.300{ }^{\circ} \mathrm{C}\right)$. At $25{ }^{\circ} \mathrm{C}-8 \mathrm{~A}$, the differential resistance is $10 \mathrm{~m} \Omega \cdot \mathrm{cm}^{2}$ compared to the estimated epilayer resistivity of $18 \mathrm{~m} \Omega \cdot \mathrm{cm}^{2}$. At this current level, the JTE is responsible for this low conductivity modulation since the JTE is in contact with the last $\mathrm{P}^{+}$ring, as illustrated in Fig. 1, and it will be justified in Section VII. At $300{ }^{\circ} \mathrm{C}-8 \mathrm{~A}$, a differential resistance of $1 \mathrm{~m} \Omega \cdot \mathrm{cm}^{2}$ is observed. As shown for the $1.2-\mathrm{kV}$ diodes, the substrate resistivity is the main contributor at this temperature. So, we can conclude that at $8 \mathrm{~A}$, the $\mathrm{P}^{+}$rings are activated, inducing a uniform conduction in the $3.5-\mathrm{kV}$ diodes. The bipolar conduction associated to the JTE is responsible for having similar $I(V)$ curves on the two designs (D5 and D6).

\section{TURN-OFF BEHAVIOR}

All diode types have been characterized in switching mode at different temperatures ranging from $25{ }^{\circ} \mathrm{C}$ to $300{ }^{\circ} \mathrm{C}$. The

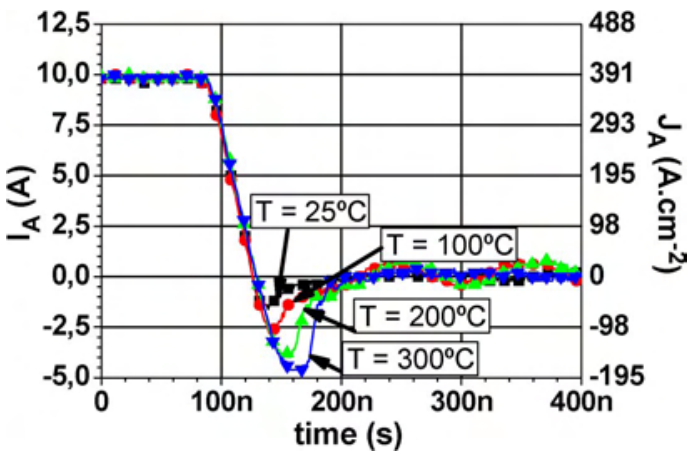

Fig. 12. Turn-off current waveforms of the 1.2-kV JBS D5 diode. Temperature range: $25^{\circ} \mathrm{C}$ to $300{ }^{\circ} \mathrm{C}$.

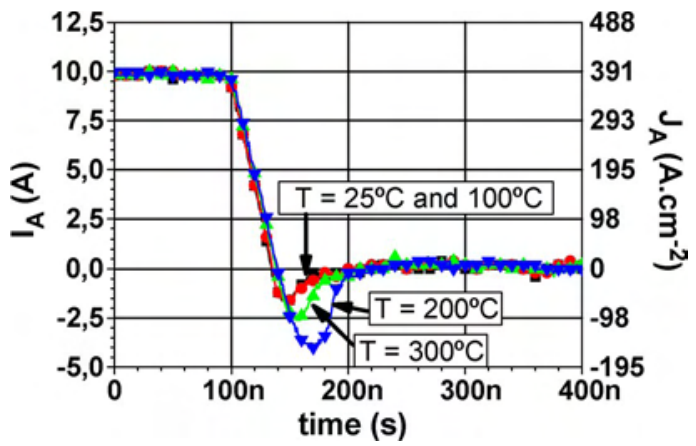

Fig. 13. Turn-off current waveforms of the 1.2-kV JBS D6 diode. Temperature range: $25^{\circ} \mathrm{C}$ to $300{ }^{\circ} \mathrm{C}$.

diodes under test were implemented in a dc/dc test converter in buck configuration [12] to characterize their switching mode using an auxiliary 45 A-1200 V Si-IGBT (IRG4PH50KPBF from International Rectifier). The turn-off current waveforms were measured with a Rogowsky probe. The switching conditions were $10 \mathrm{~A}, 300-\mathrm{V}$ supply voltage, and a $d I / d t$ of $220 \mathrm{~A} \cdot \mu \mathrm{s}^{-1}$ for the $1.2-\mathrm{kV}$ diodes. In order to decrease the self-heating effects in the $3.5-\mathrm{kV}$ rectifiers, the test current was limited to $4 \mathrm{~A}$; a supply voltage of $500 \mathrm{~V}$ and a $d I / d t$ of $160 \mathrm{~A} \cdot \mu \mathrm{s}^{-1}$ were used.

The 1.2-kV D5 and D6 diodes show an increment of the recovery charge with temperature (Figs. 12 and 13). At $25^{\circ} \mathrm{C}-$ $10 \mathrm{~A}$, the similar reverse peak current is observed for the D5 and D6 diodes and for a Schottky diode in [10], confirming the pure Schottky behavior for the JBS diodes under these conditions. At $300{ }^{\circ} \mathrm{C}-10 \mathrm{~A}$, the transient behavior is similar for D5 and D6, corroborating the full bipolar conduction. Whatever the temperature and the layout, the reverse current peak and the switch-off time of the SiC JBS diodes are much smaller than that of ultrafast Si p-i-n diodes [10].

The 3.5-kV D5 and D6 diodes show a similar increase of recovery charge with temperature (Figs. 14 and 15), as expected in a bipolar diode. Due to a low bipolar conduction at $25^{\circ} \mathrm{C}-$ $4 \mathrm{~A}$, the reverse current peak is only $5 \%$ of the nominal current. At $300{ }^{\circ} \mathrm{C}$, the ratio between the reverse peak current and the nominal current is the same for all $1.2-\mathrm{kV}$ and $3.5-\mathrm{kV}$ JBS diodes, which means that the drift region is fully conductivity modulated. So, the dynamic analysis confirms the conclusions drawn in Section III-B. 


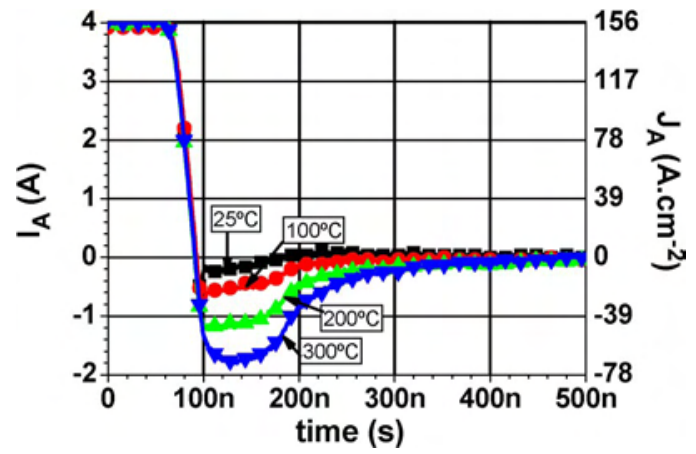

Fig. 14. Turn-off current waveforms of the $3.5-\mathrm{kV}$ JBS D5 diode. Temperature range: $25^{\circ} \mathrm{C}$ to $300^{\circ} \mathrm{C}$.

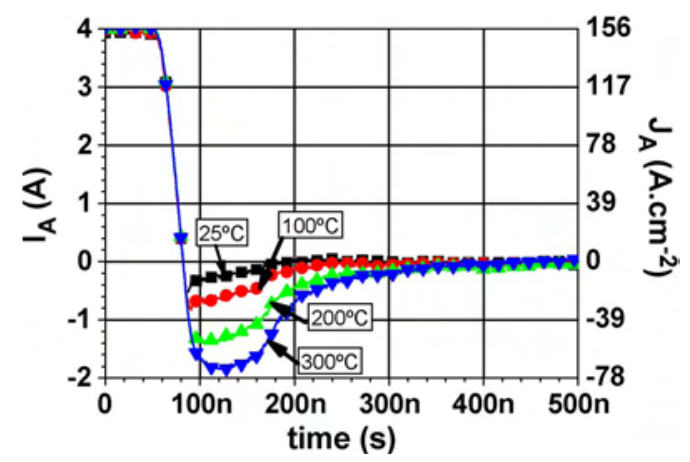

Fig. 15. Turn-off current waveforms of the $3.5-\mathrm{kV}$ JBS D6 diode. Temperature range: $25^{\circ} \mathrm{C}$ to $300{ }^{\circ} \mathrm{C}$.

\section{Surge Current Analysis}

The purpose of the surge current test is to analyze the $\mathrm{SiC}$ rectifier diode under high current stress conditions to determine the capability of the $\mathrm{SiC}$ diode to withstand high current peaks. The surge current is applied with a short duty cycle in order to permit the device temperature to return to its original value after each pulse test as it is notified in the US Military Standard MIL-STD-750E 4000 Series about the electrical characteristics test for diodes.

A sinusoidal forward current pulse with a pulse length of $10 \mathrm{~ms}$ is used for this test. The starting device temperature is $25{ }^{\circ} \mathrm{C}$. The current amplitude is increased up to the device destruction. Electrical measurements of the device are performed after each individual pulse.

A principle schematic of the test bench is shown in Fig. 16. An autotransformer T1 is used for varying the pulse amplitude. A second transformer $\mathrm{T} 2$ provides the maximum current level needed for the test.

The current pulse is manually enabled. Only one pulse is selected from the power supply by a synchronizing block (synchronous to the push button). A half-sinusoidal electric pulse is generated each time one presses the button, which is applied to the device under test (DUT). When the test button is ON, the first zero crossing of the rising sinusoidal voltage enables the power switch (thyristor) of the tester; this switches off at the following zero crossing of the falling sinusoidal voltage waveform. This way, only one test pulse for one push of the test button is allowed. The voltage and current signals are acquired by a digital oscilloscope. The final surge current value is taken as $90 \%$ of the measured destructive current value.
Fig. 17 shows the 1.2-kV-diode $V_{\mathrm{AK}}$ waveforms for a peak current of $80 \mathrm{~A}$ (the applied current waveform is shown in the insert). Below $25 \mathrm{~A}$, the $V_{\mathrm{AK}}$ forward voltage drop is lower for D5 than for D6. On the other hand, at higher current, the forward voltage drop is always higher for D5 than for D6. The surge current capability is 84 and 95 A (diode destruction occurs at 93 and 106 A) for D5 and D6, respectively. Similar results were obtained on a second batch of tested diodes. These results show that JBS diodes exhibit a significantly higher surge current capability in comparison with the 48 A sustained by pure Schottky diodes obtained under the same conditions. In any case, the obtained values are partially influenced by the package. With our test package, destruction is observed on the top-side thick aluminum metallization (anode) of the diodes.

The same experiments are realized on 3.5-kV JBS diodes, and Fig. 18 shows the evolution of $V_{\mathrm{AK}}$ under the same conditions than the $1.2-\mathrm{kV}$ diodes. Unlike $1.2-\mathrm{kV}$ diodes, $3.5-\mathrm{kV}$ rectifiers show a negative resistance behavior. This is due to the activation of the bipolar component through the $\mathrm{P}^{+}$rings. As analyzed in Section VII, there are two regions in which the bipolar conduction could be activated. The first one is the inner JTE zone in contact with the outer $\mathrm{P}^{+}$rings at relatively low $V_{\mathrm{AK}}(>3 \mathrm{~V})$, and the second one is the $\mathrm{P}^{+}$rings activated at higher $V_{\mathrm{AK}}(>7 \mathrm{~V})$. The device surge current is 81 and $89 \mathrm{~A}$ (destruction occurs at 90 and 99 A) for D5 and D6, respectively. It is much higher that in the $3.5-\mathrm{kV}$ Schottky diode (39 A) measured with the same setup.

Fig. 19 shows the $V_{\mathrm{AK}}$ forward voltage drop of $3.5-\mathrm{kV}$ D6 for 5 and 90 A (the diode destructive current is $99 \mathrm{~A}$ ). For the lower one, the conduction is bipolar (from the JTE), with the maximum $V_{\mathrm{AK}}$ value being around $6.5 \mathrm{~V}$. A different behavior is observed for a current peak of $90 \mathrm{~A}$. First, one can observe an important bipolar contribution from the diode core, accounting for the negative resistance (Fig. 19); then, the voltage drop increases due to bipolar degradations induced by SF propagation.

For the first time, it is clearly shown that a nonrepetitive current can generate bipolar degradation in SiC JBS diodes. Other degradation techniques are presented in the next section.

\section{IMPACT OF ELECTRICAL STRESS}

Diodes have been stressed in dc mode with a constant forward bias current of $8 \mathrm{~A}$ in order to degrade the diodes. For these tests, the packaged diodes were attached to a forcedconvection heat sink to limit the junction temperature to reasonable values (around $100{ }^{\circ} \mathrm{C}$ ). This is to avoid any degradation linked to high-junction temperatures. Thus, the only degradation mechanism comes from the electrical stress.

The junction temperature reached by the analyzed devices can be estimated through the dissipated power and the junctionto-case thermal resistance $\left(R_{\mathrm{TH}(j-c)}\right)$. This parameter has previously been measured by mounting the DUT over a heat sink. A calibrated K-type thermocouple allows measuring the case temperature (the package backside temperature). The diode is forward biased, and it dissipates a power that is proportional to its forward voltage drop and its forward current. First, an infrared thermography camera is used to measure the die 


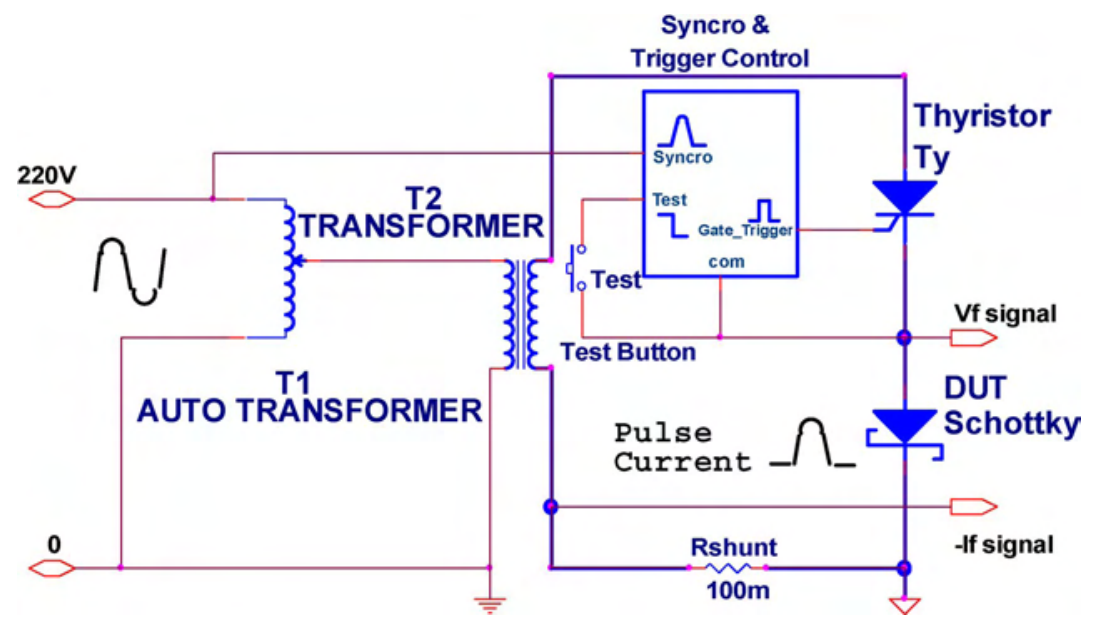

Fig. 16. Schematic of the surge current test bench.

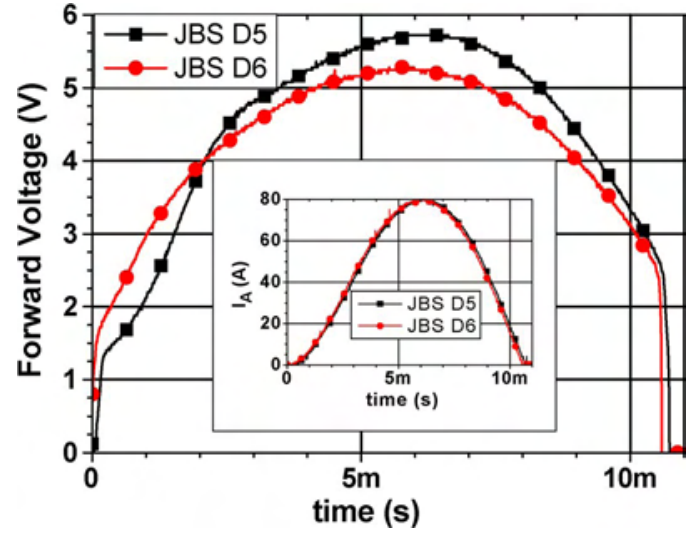

Fig. 17. $V_{\mathrm{AK}}$ waveforms at a current peak of $80 \mathrm{~A}$ for $1.2-\mathrm{kV}$ JBS D5 and D6.

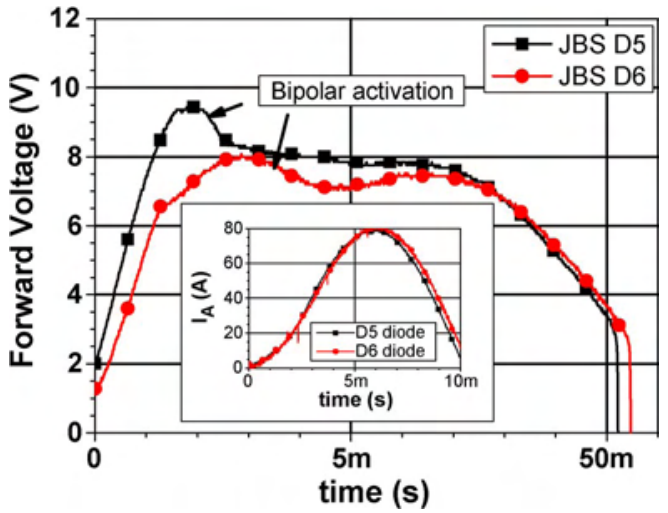

Fig. 18. $V_{\mathrm{AK}}$ waveforms of 3.5-kV JBS D5 and D6 at a current peak of $80 \mathrm{~A}$.

surface temperature, which is considered as the diode junction temperature. In order to increase the temperature measurement precision and stability, the die surface is covered with a special paint of known emissivity. For different dissipated powers (adjusted with the forward bias current), the case and the junction temperatures are acquired. This allows plotting the temperature increment (between junction and case) versus the dissipated power. The slope of the corresponding curve accounts for the $R_{\mathrm{TH}(j-c)}$ value.

From the described measurement procedure, the $R_{\mathrm{TH}(j-c)}$ values for $1.2-\mathrm{kV} \mathrm{D} 5$ and D6 are 1.8 and $1.3 \mathrm{~K} \cdot \mathrm{W}^{-1}$, respec-

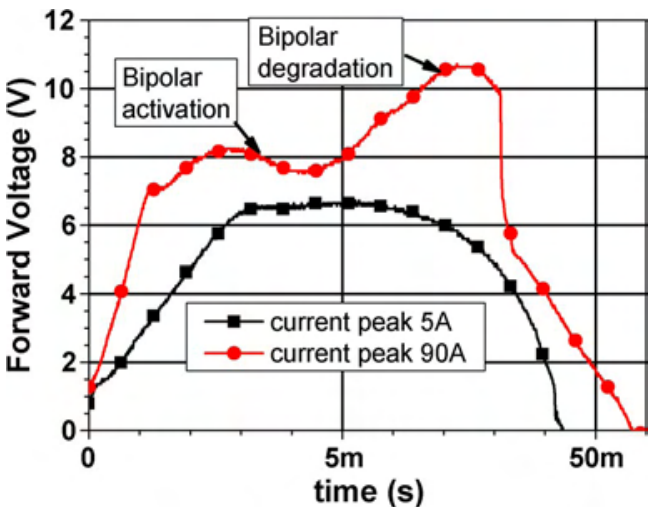

Fig. 19. $V_{\mathrm{AK}}$ waveforms of $3.5-\mathrm{kV}$ JBS D6 at two current peaks (5 and $90 \mathrm{~A})$.

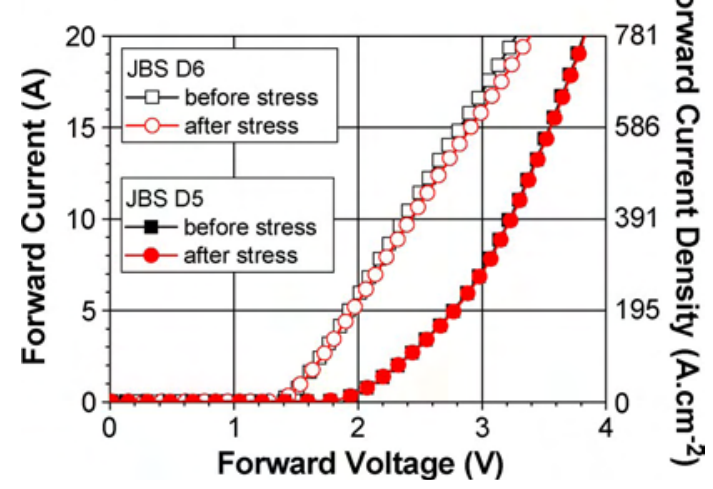

Fig. 20. Evolution of the forward electrical characteristics of 1.2-kV D5 and D6 JBS diodes during 50-h de stress at $8 \mathrm{~A}$.

tively. Taking into account that the reached case temperatures are $39{ }^{\circ} \mathrm{C}$ for D5 and $31{ }^{\circ} \mathrm{C}$ for D6 for a current of $8 \mathrm{~A}$, the junction temperatures during dc stress at such current are $82{ }^{\circ} \mathrm{C}$ for D5 and $52{ }^{\circ} \mathrm{C}$ for D6. At this junction temperature and current bias, D5 is working in a bipolar conduction mode, and D6 is working in a Schottky conduction mode.

Fig. 20 shows the evolution of the forward characteristics of both $1.2-\mathrm{kV}$ D5 and D6 diodes after 50-h dc stress. For the two different conduction modes (bipolar for D5 and Schottky for D6), the $I(V)$ curves do not show any voltage drop shift. 


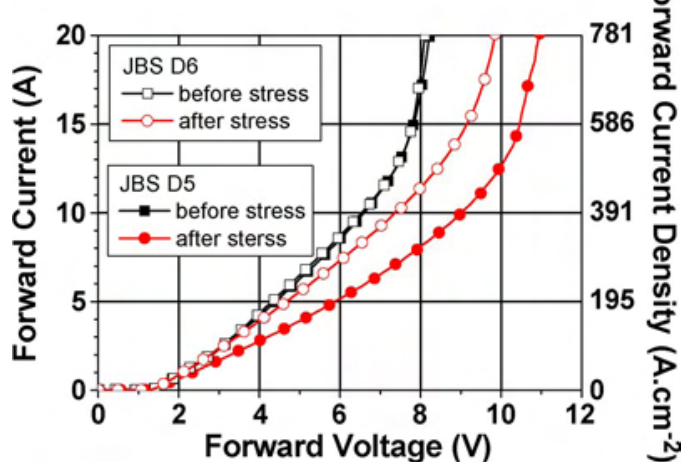

Fig. 21. Evolution of the forward electrical characteristics of 3.5-kV D5 and D6 JBS diodes during $50-\mathrm{h}$ de stress at $8 \mathrm{~A}$.

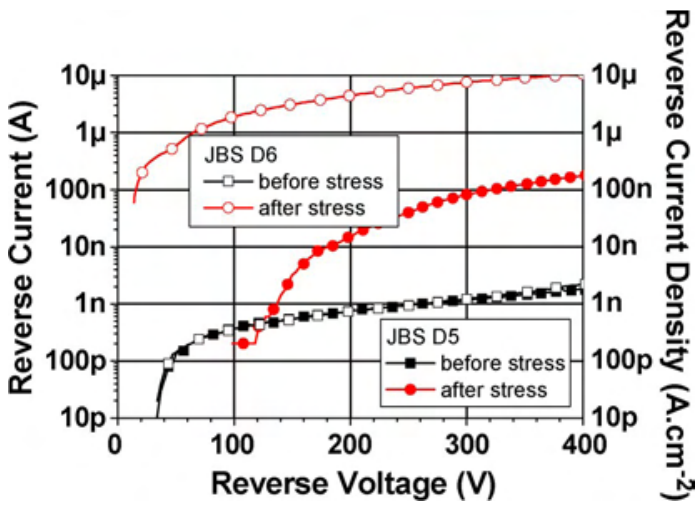

Fig. 22. Evolution of the reverse electrical characteristics up to $400 \mathrm{~V}$ of 3.5-kV JBS D5 and D6 diodes during 50-h stress at $8 \mathrm{~A}$.

Therefore, it can be concluded that the $1.2-\mathrm{kV}$ diodes do not exhibit any degradation produced by the expansion of the SFs. The 1.2-kV diodes have also been stressed at high current with a $250-\mu$ s repetitive pulsed current with low duty cycle $(2 \%)$ during $1 \mathrm{~h}$. In this case, both diodes enter in bipolar conduction mode. Neither D5 nor D6 exhibits any bipolar degradation after current stress up to 25 and $30 \mathrm{~A}$, respectively. In addition, at very high pulsed current density $\left(4500 \mathrm{~A} \cdot \mathrm{cm}^{-2}\right)$ stress, the 1.2-kV JBS diodes do not show any bipolar degradation.

With $1.7 \mathrm{~K} \cdot \mathrm{W}^{-1}$ as $R_{\mathrm{TH}(\mathrm{j}-\mathrm{c})}$ for $\mathrm{D} 5$ and $\mathrm{D} 63.5-\mathrm{kV}$ diodes, the evaluated junction temperature reaches $111{ }^{\circ} \mathrm{C}$ when the diode is under stress at $8 \mathrm{~A}$ and the case temperature reaches $30{ }^{\circ} \mathrm{C}$. Fig. 21 reports the electrical characteristics of these diodes before and after 50-h dc stress. The two diodes show a voltage drop shift. As shown in Section VII, this is due to a bipolar degradation generated by the expansion of the SFs. Other diodes exhibit similar variation independently they are D5 and D6 diodes. Therefore, it cannot be concluded that the design has any impact on bipolar degradation for the $3.5 \mathrm{kV}$ diodes than the $1.2 \mathrm{kV}$ diodes since the epilayer resistivity has impact on the Schottky conduction. In addition, electrical $\mathrm{dc}$ stress at $4 \mathrm{~A}$ has been performed to decrease the junction temperature, reaching $57^{\circ} \mathrm{C}$. Under these conditions, a similar voltage drop shift has been observed for the 3.5-kV D5 and D6 diodes. For example, at $15 \mathrm{~A}, V_{\mathrm{AK}}$ is $8 \mathrm{~V}$ before stress and increases up to $10.2 \mathrm{~V}$ after stress.

Fig. 22 shows the reverse characteristics for JBS diodes before and after stress. It is clear that if the device shows
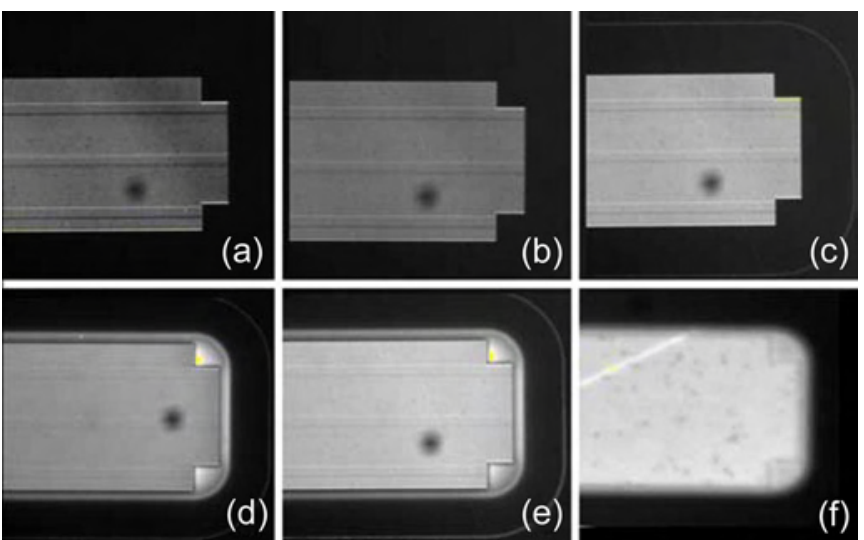

Fig. 23. Electroluminescence of a 1.2-kV JBS diode in forward mode. (a) and (b) Schottky mode activation at 2.7 and $3.6 \mathrm{~V}$. (c) Beginning of the bipolar mode from the edge at $4.4 \mathrm{~V}$. (d) and (e) Schottky and bipolar modes from bulk and only bipolar from the edge at 4.7 and 5 V. (f) High injection level bipolar mode at $6 \mathrm{~V}$.

degradation in forward mode, the leakage current increases after the stress. Moreover, if the forward voltage shift increases, the leakage current also increases, as illustrated in Fig. 22 for the D6 diode. Physically, the expansion of the SFs generates recombination centers. Accordingly, the carrier life time is decreased, and therefore, at a given current, the voltage increases after the stress. In reverse mode, the leakage current induced by the electrical field also increases due to these recombination centers, which generate electron-hole pairs. In conclusion, the $3.5-\mathrm{kV}$ JBS diodes show degradations that can be explained in terms of the SF expansion.

\section{ELECTROLUMinESCENCE}

To understand the electrical behavior of the stressed JBS diodes, an electroluminescence microscopy technique through the back-side polished diodes was used [13]. The diodes from a polished back-side $1 / 4$ wafer were mounted on a different package than the one used for electrical tests. Since the $\mathrm{n}^{+}$ substrate is highly doped, and since the surface used to contact the back side to the package covers half of the entire surface, we assume that the contribution of the back-side resistance is not the main contribution of the total resistance. However, because the package used for electroluminescence measurement was not optimized for high current density and temperature, it was impossible to obtain the same $I-V \mathrm{~s}$ than in the previous electrical test. However, despite a globally higher resistance of the diodes, the electroluminescence technique allowed us to understand the behavior of the carriers in Schottky and bipolar mode, and to link it with the previous electrical measurements.

For all the characterized 1.2-kV JBS diodes, an orange-red luminescence corresponding to the $1.5-\mathrm{eV}$ Schottky barrier height $\mathrm{Ni}-\mathrm{SiC}$ predominates below the bipolar mode activation. This luminescence is located under each individual "Schottky finger" in the center of the diode [Fig. 23(a) and (b)] [14]. At higher bias, the bipolar conduction starts at the structure periphery [Fig. 23(c) and (d)] and then is activated in the bulk thanks to an efficient conductivity modulation in the drift region [Fig. 23(e)]. This low drift layer resistance leads to a 


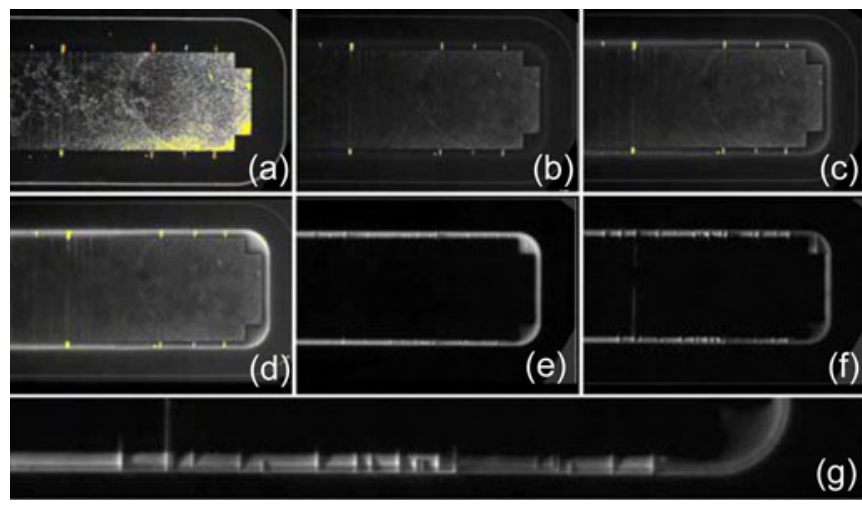

Fig. 24. Electroluminescence of a 3.5-kV JBS diode in forward mode. (a) Schottky mode activation at $2.4 \mathrm{~V}$. (b)-(d) Schottky and bipolar modes at 2.5, 2.6, and $2.7 \mathrm{~V}$. (e) and (f) Bipolar mode activation only from the edge at 3.3 and $4 \mathrm{~V}$. (g) Zoom of (f) to illustrate the structural degradation of the bipolar device.

uniform bipolar current across the whole active area at very high injection level [Fig. 23(f)].

A different behavior is observed for $3.5-\mathrm{kV}$ JBS diodes. Indeed, at low bias, the carrier transport is similar to that on the $1.2-\mathrm{kV}$ diodes, the current from the bulk predominates [Fig. 24(a) and (b)], and then a bipolar current is driven by the edge of the diode added to the previous Schottky contribution from the bulk [Fig. 24(c) and (d)]. However, the main difference comes from the fact that the bipolar regime in the bulk is not activated: at very high injection level, most of the current (bipolar) is due to the diode edge contribution [Fig. 24(e) and (f)]. This behavior is probably due to a higher carrier injection efficiency through the thick low-doped p-type JTE-implanted layer of $0.5 \mu \mathrm{m}$ in comparison with $0.2 \mu \mathrm{m}$ as the $\mathrm{P}^{+}$junction depth. Indeed, the damages at the interface between the $\mathrm{P}^{+}$ implanted region and the $n$ - base epitaxial layer induced by the Al implantation strongly depend on the dose. The higher the dose, the higher the interface trap density that lowers the carrier injection efficiency. Almost all the currents passing through the edges of the diode, where the Al dose is lower, lead to the formation/extension of SFs in the drift epilayer, locally reducing the bipolar conductivity. This phenomenon explains the current degradation occurring when applying a forward dc stress [Fig. 24(f) and (g)].

Since the high-injection current density of the 1.2-kV JBS diodes is much lower than the 3.5-kV JBS diodes, the SF formation probability is much lower, as experimentally confirmed. Indeed, almost no SFs on any $1.2-\mathrm{kV}$ diode were revealed by electroluminescence even under high thermal and dc stresses, which confirms their very high reliability already underlined in Section VI.

\section{CONCLUSION}

This paper has dealt with the electrical performance of 1.2- and 3.5-kV SiC JBS diodes. Two layouts have been considered with different $\mathrm{P}^{+}$ring lengths and spacings between adjacent $\mathrm{P}^{+}$rings. Concerning the forward characteristics, the $1.2-\mathrm{kV}$ diodes show similar electrical performance (forward $I-V$ curves at $300{ }^{\circ} \mathrm{C}$, reverse characteristics, switch off, surge current capability, and reliability issues), but the diode having the larger Schottky component exhibits better performance in forward mode at $25{ }^{\circ} \mathrm{C}$. Therefore, this design is preferable for $1.2-\mathrm{kV}$ diodes. Regarding the $3.5-\mathrm{kV}$ diodes, their forward characteristics are similar independent of the layout. This behavior is due to the bipolar current associated to the structure periphery, which has been evidenced by electroluminescence measurements. In reverse mode at $500 \mathrm{~V}-300{ }^{\circ} \mathrm{C}$, the 3.5 - and 1.2-kV diodes exhibit a leakage current lower than $100 \mathrm{nA}$ and $10 \mu \mathrm{A}$, respectively. This outstanding reverse behavior cannot be found in Si-based devices. In switch mode, both diodes $\mathrm{SiC}$ $(1.2$ and $3.5 \mathrm{kV})$ exhibit a reverse current peak lower than $50 \%$ of the nominal current at $300{ }^{\circ} \mathrm{C}$ and smaller turn-off time than $\mathrm{Si}$ rectifiers despite that the bipolar conduction of the SiC JBS diodes is activated. The surge current capability of the 1.2- and $3.5-\mathrm{kV}$ JBS diodes is higher than $80 \mathrm{~A}$, which is two times higher than that of equivalent $4 \mathrm{H}-\mathrm{SiC}$ Schottky diodes. Moreover, for the first time, we have detected bipolar degradations in 3.5-kV JBS diodes under a nonrepetitive electrical pulse. Diodes have been stressed in dc mode during $50 \mathrm{~h}$, and no degradation is observed in 1.2-kV diodes. For $1.2-\mathrm{kV}$ diodes, no bipolar degradation is observed after a very high pulse current density $\left(4500 \mathrm{~A} \cdot \mathrm{cm}^{-2}\right)$ stress. Nevertheless, the $3.5-\mathrm{kV}$ diodes suffer some degradation confirmed by electroluminescence measurements.

Due to their bipolar mode conduction, our JBS designs outperform any SiC Schottky diode in terms of on-resistance, reverse leakage current, and surge current capability. Furthermore, thanks to their Schottky behavior, they outperform the $\mathrm{SiC}$ p-i-n diodes in term of reliability, low $V_{\mathrm{AK}}$, turn-off losses, and switching speed. Depending on the current level and the working temperature, the SiC JBS diode seems to be the best compromise as a rectifier for power electronic applications.

\section{ACKNOWLEDGMENT}

The authors would like to thank the Ampere Laboratory, Lyon, France, and IMEP-CNRS, Grenoble, France, for its help in high-voltage and electroluminescence measurements, respectively.

\section{REFERENCES}

[1] Y. M. Tairov and V. F. Tsvetkov, "Investigation of growth processes of ingots of silicon carbide single-crystals," J. Cryst. Growth, vol. 43, no. 2, pp. 209-212, Mar. 1978.

[2] J. A. Powell, D. J. Larkin, L. G. Matus, W. J. Choyke, J. L. Bradshaw, L. Henderson, M. Yoganathan, J. Yang, and P. Pirouz, "Growth of high quality $6 \mathrm{H}-\mathrm{SiC}$ epitaxial films on vicinal (0001) 6H-SiC wafers," Appl. Phys. Lett., vol. 56, no. 15, pp. 1442-1444, Apr. 1990.

[3] B. Lu, W. Dong, Q. Zhao, and F. C. Lee, "Performance evaluation of CoolMOS/sup /spl trade// and SiC diode for single-phase power factor correction applications," in Proc. 18th Annu. IEEE APEC, 2003, vol. 2, pp. 651-657.

[4] R. Rupp, M. Treu, S. Voss, F. Bjork, and T. Reimann, “"2nd Generation' SiC Schottky diodes: A new benchmark in SiC device ruggedness," in Proc. IEEE Int. Symp. Power Semicond. Devices IC's, 2006, pp. 1-4.

[5] F. Dahlquist, J. O. Svedberg, C. M. Zetterling, M. Ostling, B. Breitholtz, and $\mathrm{H}$. Lendenmann, "A $2.8 \mathrm{kV}$, forward drop JBS diode with low leakage," Mater. Sci. Forum, vol. 338-342, pp. 1179-1182, 2000.

[6] D. Peters, P. Friedrichs, R. Schorner, and D. Stephani, "Comparison of $4 \mathrm{H}-\mathrm{SiC}$ pn, pinch and Schottky diodes for the $3 \mathrm{kV}$ range," Mater. Sci. Forum, vol. 389-393, pp. 1125-1128, 2002.

[7] J. P. Bergman, H. Jakobsson, L. Storasta, F. H. C. Carlsson, B. Magnusson, S. Sridhara, G. Pozina, H. Lendenmann, and E. Janzen, "Characterisation 
and defects in silicon carbide," Mater. Sci. Forum, vol. 389-393, pp. 9-14, 2002.

[8] R. Perez, N. Mestres, J. Montserrat, D. Tournier, and P. Godignon, "Barrier inhomogeneities and electrical characteristics of $\mathrm{Ni} / \mathrm{Ti}$ bilayer Schottky contacts on $4 \mathrm{H}-\mathrm{SiC}$ after high temperature treatments," Phys. Stat. Sol. (a), Appl. Mater. Sci., vol. 202, no. 4, pp. 692-697, Mar. 2005.

[9] F. Roccaforte, F. La Via, V. Raineri, P. Musumeci, L. Calcagno, and G. G. Condorelli, "Highly reproducible ideal SiC Schottky rectifiers: Effects of surface preparation and thermal annealing on the $\mathrm{Ni} / 6 \mathrm{H}-\mathrm{SiC}$ barrier height," Appl. Phys. A, Mater. Sci. Process., vol. 77, no. 6, pp. 827833, Nov. 2003.

[10] P. Brosselard, X. Jordà, M. Vellvehí, A. Perez Tomas, P. Godignon, and J. Millán, "1.2 kV rectifiers thermal behaviour: Comparison between Si PiN, 4H-SiC Schottky and JBS diodes," in Proc. Eur. Power Electron. Conf., Aalborg, Denmark, 2007, pp. 1-9.

[11] P. Brosselard, N. Camara, J. Hassan, X. Jordà, P. Bergman, J. Montserrat, and J. Millán, "3.3 kV-10A 4H-SiC PiN diodes," in Proc. Int. Conf. Silicon Carbide Related Mater., Kyoto, Japan, 2007.

[12] X. Jordà, X. Dalmau, P. Godignon, M. Vellvehi, X. Perpiñà, S. Hidalgo, and J. Millán, "Modular characterisation system for power devices," in Proc. 6th ISPS, Prague, Czeck Republic, 2002, pp. 199-203.

[13] N. Camara, A. Thuaire, E. Bano, and K. Zekentes, "Forward-bias degradation in $4 \mathrm{H}-\mathrm{SiC} \mathrm{p}(+) \mathrm{nn}(+)$ diodes: Influence of the mesa etching," Mater. Sci. Forum, vol. 483-485, pp. 773-776, 2005.

[14] Q. ul-Wahab, F. H. C. Carlsson, J. P. Bergman, and E. Janzén, Electroluminescence from 4H-SiC Schottky diodes. San Francisco, CA: MRS, 2000.

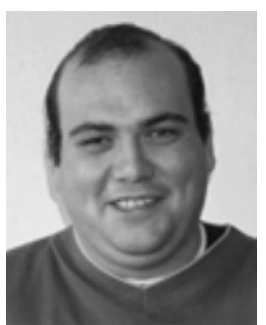

Pierre Brosselard was born in Roanne, France, in 1977. He received the B.S. degree from the University of Lyon, Lyon, France, in 2001 and the $\mathrm{Ph} . \mathrm{D}$. degree from the Institut National des Sciences Apliquées de Lyon, Lyon, in 2004.

From 2001 to 2005, he was with the Centre de Génie Eléctrique de Lyon, Equipe de Composants de Puissance et Applications, Lyon, where he worked on $\mathrm{SiC}$ power devices. Since 2005, he has been with the Power Electronics Group, Centro Nacional de Microelectrónica-Consejo Superior de Investigaciones Científicas, Barcelona, Spain. He has authored and coauthored more than 40 research papers in journals and conference proceedings. His current research activity deals with the modeling, design, and characterization of power semiconductor devices.

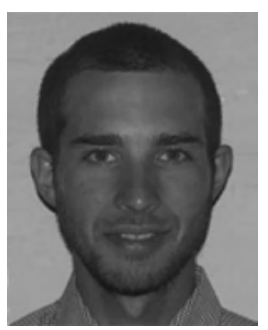

Nicolas Camara received the Dipl. degree in physics from the Engineering University of Marseille, Marseille, France, in 2001 and the Ph.D. degree in nanomicrotechnology from both the Polytechnics of Grenoble, Grenoble, France, and the University of Crete, Heraklion, Greece, in 2006.

$\mathrm{He}$ is currently a Post-Doctoral Researcher with the Centro Nacional de Microelectrónica-Instituto de Microelectrónica de Barcelona, Barcelona, Spain. $\mathrm{He}$ is the author or coauthor of more than 20 journals and conference proceedings. His current research interests include $\mathrm{SiC}$ and graphene technology, device, characterization, and modeling.

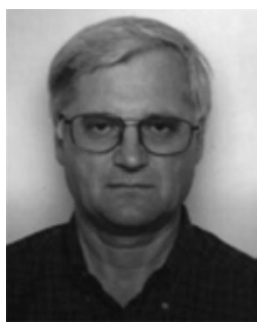

Viorel Banu was born in 1953. He received the M.Sc. degree in microelectronics and semiconductor devices from the University Politehnica of Bucharest, Bucharest, Romania, in 1978.

In 1978, he was with IPRS-Baneasa, Bucharest, where he was involved in several development projects for the production of high-power devices (thyristors and diodes). Until 1998, he was responsible for high-vacuum thin-film deposition and the development of high-power semiconductor technology. In 1999, he was appointed Leader of the Department of High Power Devices and Applications. In 2001, he was an Associate Designer for Bi-CMOS analog-mixed integrated circuits with O2Micro-Ltd. Since June 2007, he has been with the Group of Power Devices and Systems, Centro Nacional de Microelectrónica, Barcelona, Spain, where he is currently acting as Technology Engineer for wide-bandgap semiconductors.

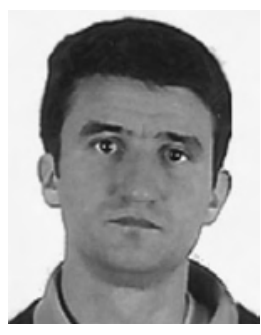

Xavier Jordà was born in Barcelona, Spain, in 1967. $\mathrm{He}$ received the B.S. degree from the Universitat Autònoma de Barcelona, Barcelona, in 1990 and the $\mathrm{Ph} . \mathrm{D}$. degree from the Institut National des Sciences Apliquées de Lyon, Lyon, France, in 1995.

From 1990 to 1995, he was with the Centre de Génie Eléctrique de Lyon-Equipe de Composants de Puissance et Applications, Lyon, where he worked on the vector control of induction motors, threephase phase-width modulation (PWM) methods, and ac drives. Since 1995, he has been with the Power Electronics Group, Centro Nacional de Microelectrónica-Consejo Superior de Investigaciones Científicas, National Center of Microelectronics, Barcelona. His current research activity deals with thermal management, modeling, and electrothermal characterization of power semiconductor devices and systems. He has authored and coauthored more than 100 research papers in journal and conference proceedings.

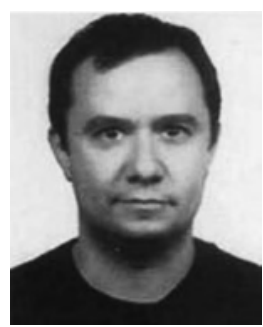

Miquel Vellvehi was born in Mataró, Spain, in 1968. $\mathrm{He}$ received the B.S. degree in physics and the Ph.D. degree in electrical engineering from the Universitat Autònoma de Barcelona, Barcelona, Spain, in 1992 and 1997, respectively. His Ph.D. dissertation addresses the analysis of the thermal behavior of lateral insulated gate bipolar transistors.

Since 1993, he has been with the Power Electronics Group, Centro Nacional de MicroelectrónicaConsejo Superior de Investigaciones Científicas (CNM-CSIC), Barcelona. He has authored and coauthored more than 100 research papers in journal and conference proceedings. From 1993 to 1998, his research activities include technology, modeling, and numerical simulation of MOS-controlled power semiconductor devices. Since 1999, his main research activity deals with the electrothermal characterization and modelization of power semiconductor devices and circuits.

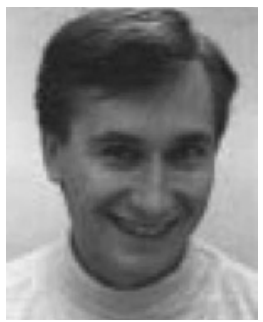

Philippe Godignon received the Ph.D. degree in electrical engineering from Institut National des Sciences Appliquées de Lyon (INSA), Lyon, France, in 1993.

Since 1990, he has been with the Power Device and System Group, Centro Nacional de Microelectronica (CNM), Barcelona, Spain, where he has been working on $\mathrm{Si}$ and $\mathrm{SiC}$ IGBT/VDMOS device design and technologies. His competence covers the device technological process development and mask design as well as the electrical characterization. He has authored more than 60 publications and conference proceedings on SiC.

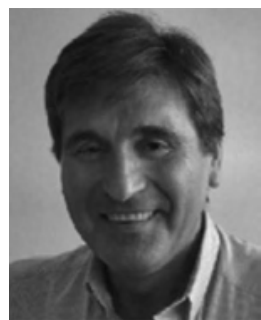

José Millán (M'91) received the B.S. and Ph.D. degrees from the Universitat Autònoma de Barcelona (UAB), Barcelona, Spain, in 1971 and 1981, respectively.

From 1981 to 1987, he was an Assistant Professor with UAB, where he taught physics and electronics and several courses on microelectronics for postgraduate students. In 1987, he joined the Centro Nacional de Microelectronica (CNM), Barcelona, where he created the Power MOS Division. He is currently a Professor and the Vice-Director of the CNM. He has served as CNM Manager in several EU-financed research projects. $\mathrm{He}$ has authored more than 87 publications and 142 conference proceedings. His research activity deals with the physics, technology, and modeling of power semiconductor devices, and SiC-based devices. 